\title{
Triple junction diffusion and plastic flow in fine-grained materials
}

\author{
A.A. Fedorov, M.Yu. Gutkin, I.A. Ovid'ko * \\ Institute of Problems of Mechanical Engineering, Russian Academy of Sciences, Bolshoj 61, Vasil. Ostrov, St. Petersburg 199178, Russia
}

Received 8 November 2001; received in revised form 30 January 2002; accepted 27 March 2002

\begin{abstract}
A theoretical model is suggested which describes the yield stress dependence on grain size in fine-grained materials, based upon competition between conventional dislocation slip, grain boundary diffusional creep (Coble creep) and triple junction diffusional creep. In the framework of the model, the contribution of diffusional creep mechanisms to plastic deformation increases with reduction of grain size, causing the abnormal Hall-Petch dependence in the range of small grains. A grain size distribution is incorporated into the consideration to account for a distribution of grain sizes occurring in real specimens. The results of the model are compared with experimental data from $\mathrm{Cu}$ and shown to be in good agreement. () 2002 Acta Materialia Inc. Published by Elsevier Science Ltd. All rights reserved.
\end{abstract}

Keywords: Diffusion; Grain boundaries; Mechanical properties

\section{Introduction}

Nanostructured materials exhibiting unique physical, mechanical and chemical properties represent the subject of intensive fundamental and applied research, e.g. [1-6]. Of the special interest for numerous applications are the outstanding mechanical properties (high strength, good fatigue resistance, ductility) of nanocrystalline materials, which are essentially different from those of conventional coarse-grained polycrystals (for a review, see [4-6]). One of the specific features of deformation processes in nanocrystalline materials manifests itself in deviations from the known grain size

\footnotetext{
${ }^{*}$ Corresponding author. Tel.: +7-812-321-4764; fax: +7-812321-4771.

E-mail address: ovidko@def.ipme.ru (I.A. Ovid'ko).
}

scaling relations. A conventional Hall-Petch relationship for the strengthening of materials by grain refinement describes the relationship between the yield stress $\sigma$ and the mean grain size $d$ as follows $[7,8]$ :

$\sigma=\sigma_{0}+k d^{-1 / 2}$,

where $\sigma_{0}$ denotes the friction stress needed to move individual dislocations, and $k$ is a material dependent constant. This relationship is characterized by the constant Hall-Petch gradient $\mathrm{d} \sigma /$ $\mathrm{d}\left(d^{-1 / 2}\right)$ in the case of coarse-grained polycrystals with the grain size $d$ being typically from $1 \mu \mathrm{m}$ and larger. The three types of behavior have been experimentally documented for nanocrystalline materials: a constant positive Hall-Petch gradient as with coarse-grained polycrystals, a decreasing positive gradient at some critical grain size and a 
negative gradient below some critical grain size [4-6].

At present, the nature of the deviations from the conventional Hall-Petch grain size scaling relation in nanocrystalline materials is the subject of controversy; see e.g., [6,9-21]. The generic idea of the most models of the abnormal Hall-Petch relationship is that the grain boundary phase provides the effective action of deformation mechanism(s) in nanocrystalline materials, which is (are) different from the conventional lattice dislocation slip realized in coarse-grained polycrystals. Such plastic deformation mechanisms competing with the lattice dislocation slip in nanocrystalline materials are grain boundary sliding and diffusional mass transfer occurring predominantly via grain boundary diffusion. In particular, recently, Masumura et al. [16] have elaborated a theoretical model effectively describing the yield stress dependence on grain size $d$ in fine-grained materials, based upon competition between conventional lattice dislocation slip, bulk diffusional creep and grain boundary diffusional creep (Coble creep). In doing so, they were the first who take into account a grain size distribution occurring in real specimens and strongly influencing the yield stress dependence on grain size.

However, as with grain boundary diffusion, triple junction diffusion is capable of playing the very important role in plastically deformed nanocrystalline materials where the volume fraction of triple junctions of grain boundaries is extremely high. Actually, in recent years, it has been definitely recognized that triple junctions of grain boundaries have the structure and properties being different from those of the grain boundaries that they adjoin [22]. From experimental data and theoretical models [23-29] it follows that triple junctions of grain boundaries play the role as enhanced diffusivity tubes, nuclei of the second phase segregation, strengthening elements and sources of lattice dislocations during plastic deformation, and drag centers of grain boundary migration during re-crystallization processes. In particular, the outstanding diffusional properties exhibited by nanocrystalline materials [30-33] are viewed to be related to the effect of the highly enhanced diffusion along triple junction tubes [34]. The main aim of this paper is to suggest a theoretical model of the abnormal Hall-Petch effect in nanocrystalline materials, based upon the idea on competition between conventional lattice dislocation slip, grain boundary diffusional creep and triple junction diffusional creep. In our model we will take into account a grain size distribution inherent to real fine-grained materials.

\section{Model}

The key basic statements of the suggested model of plastic deformation processes in finegrained materials are as follows:

(1) Materials with a relatively large grain size obey the classical Hall-Petch relationship (1).

(2) Plastic deformation in materials with a small grain size occurs via diffusional creep mechanisms provided by enhanced diffusion along grain boundaries and their triple junctions. In this situation, the plastic strain rate $\dot{\varepsilon}$ has the two basic constituents:

$\dot{\varepsilon}=\dot{\varepsilon}_{\mathrm{c}}+\dot{\varepsilon}_{\mathrm{tj}}$

Here $\dot{\varepsilon}_{\mathrm{c}}$ is the plastic strain rate associated with grain boundary diffusional creep (Coble creep) and $\dot{\varepsilon}_{\mathrm{tj}}$ is the plastic strain rate associated with triple junction diffusional creep considered in detail by Rabukhin [35]. The Coble creep strain rate is given as follows (e.g. [11]):

$\dot{\varepsilon}_{\mathrm{c}}=14 \pi \frac{\Omega \sigma w}{k_{\mathrm{B}} T} \frac{D_{\mathrm{gb}}}{d^{3}}$,

where $k_{\mathrm{B}}$ denotes the Boltzmann constant, $T$ the absolute temperature, $\Omega$ the atomic volume, $w$ the grain boundary thickness, $\sigma$ the applied stress, and $D_{\mathrm{gb}}$ the coefficient of grain boundary self-diffusion. The creep associated with enhanced triple junction diffusion is characterized by the plastic strain rate [35]

$\dot{\varepsilon}_{\mathrm{tj}}=20 \frac{\Omega \sigma l \delta}{k_{\mathrm{B}} T} \frac{D_{\mathrm{tj}}}{d^{4}}$,

where $D_{\mathrm{tj}}$ is the coefficient of triple junction selfdiffusion, $\delta$ is the triple junction tube diameter, and $l$ is the characteristic length of distorted regions of grain boundaries in vicinity of their triple junc- 
tions. (Grain boundary dislocations commonly are stopped by triple junctions in plastically deformed poly- and nanocrystalline solids, in which case the length $l$ characterizes the grain boundary regions with stopped boundary dislocations in vicinity of triple junctions. Following [35], these dislocationrich regions of grain boundaries affect the triple junction diffusional creep, in which case the length scale $l$ appears in (4) for the corresponding strain rate.) With (3) and (4) substituted into (2), we have the following formula for the yield stress that characterizes the diffusional deformation mechanisms in materials with a small grain size:

$\sigma_{\text {diff }}=\frac{\dot{\varepsilon} d^{4} k_{\mathrm{B}} T}{2 \Omega\left(10 \delta l D_{\mathrm{tj}}+7 \pi w d D_{\mathrm{gb}}\right)}$.

(3) The statistical nature of the grain size, as in paper [16], is taken into account in a fine-grained material. Following [16], the volume $v$ of the grains is assumed to be log-normally distributed

$f(v)=\frac{1}{v \sqrt{2 \pi s^{2}}} \exp \left(-\frac{\left(\ln v-m_{\operatorname{lnv}}\right)^{2}}{2 s^{2}}\right)$,

where $m_{\operatorname{lnv}}$ and $s$ are the mean value and standard deviations of $\ln v$, respectively, and where $m_{\mathrm{v}}$ is the mean volume of all the grains

$m_{\mathrm{v}}=\int_{0}^{\infty} v f(v) \mathrm{d} v=\exp \left(m_{\operatorname{lnv}}+\frac{s^{2}}{2}\right)$.

The yield stress $\sigma$ is thus determined not from the average grain size, but from the whole distribution.

(4) Finally, it is assumed that a grain size $d^{*}$ exists at which value the classical Hall-Petch mechanism switches to the diffusional mechanisms, $\sigma_{\mathrm{hp}}=\sigma_{\text {diff }}$ at $d=d^{*}$. Using formulae (1) and (5) with $d=d^{*}$, we have

$\sigma_{0}+k\left(d^{*}\right)^{-1 / 2}=\frac{\dot{\varepsilon}\left(d^{*}\right)^{4} k_{\mathrm{B}} T}{2 \Omega\left(10 \delta l D_{\mathrm{tj}}+7 \pi w d^{*} D_{\mathrm{gb}}\right)}$.

With a distribution (6) in grain size, we find the yield stress to be given as

$\left\langle\sigma_{\text {tot }}\right\rangle=F_{\text {hp }}+F_{\text {diff }}$, where

$F_{\mathrm{hp}}=\frac{1}{m_{\mathrm{v}}} \int_{v^{*}}^{\infty} \sigma_{\mathrm{hp}} v f(v) \mathrm{d} v$,

$F_{\text {diff }}=\frac{1}{m_{\mathrm{v}}} \int_{0}^{v^{*}} \sigma_{\text {diff }} v f(v) \mathrm{d} v$,

and $v^{*}=\left(d^{*}\right)^{3}$.

\section{Results}

For characteristic values of parameters of copper $[11,13,16,35,39] D_{\mathrm{gb}} \approx 2.6 \times 10^{-20} \mathrm{~m}^{2} \mathrm{~s}^{-1}, \Omega=$ $1.18 \times 10^{-29} \mathrm{~m}^{3}, k_{\mathrm{B}}=1.38 \times 10^{-23} \mathrm{~J} \mathrm{~K}^{-1}, T=290$ $\mathrm{K}, \sigma_{0}=200 \mathrm{MPa}, k=1750 \mathrm{MPa} \mathrm{nm}^{1 / 2}, s=1$, $w=2 b, l=5 b, \delta=3 b$, and $b=0.3 \mathrm{~nm}$ (where $b$ is the crystal lattice parameter), from formulae (9)(11) we have numerically calculated the dependence $\sigma\left(d^{-1 / 2}\right)$ shown in Fig. 1. In doing so, $d^{*}$ given by the condition $\sigma_{\mathrm{hp}}\left(d^{*}\right)=\sigma_{\mathrm{diff}}\left(d^{*}\right)$ is $\approx 18 \mathrm{~nm}$. This estimate is close to that $\left(d^{*}=14\right.$ $\mathrm{nm})$ of Masumura et al. [16]. The dependences $\sigma\left(d^{-1 / 2}\right)$ taking into account respectively the only grain boundary diffusional creep (dashed curve) and both the grain boundary and triple junction

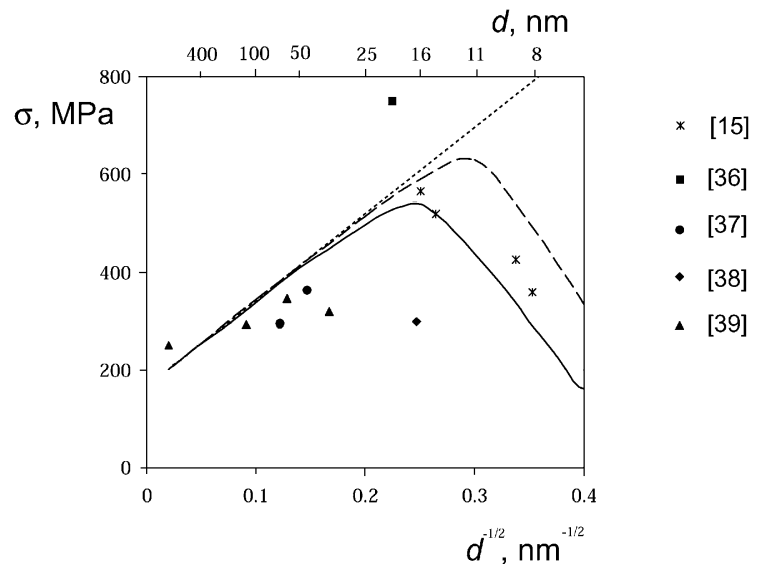

Fig. 1. Yield stress $\sigma$ as a function of the inverse square root of average grain size $d$ in copper. Experimental data [15,36-39] along with calculated values are shown. Solid and dashed curves correspond to model calculations with the contribution of triple junction diffusional creep respectively taken and not taken into account. The classical Hall-Petch dependence is shown as dotted line. 
diffusional creep mechanisms (solid curve) are shown in Fig. 1. For $d \geqslant 20 \mathrm{~nm}$, both dashed and solid curves are close. At the same time, the triple junction diffusional creep causes the essential contribution to high deviations of the $\sigma\left(d^{-1 / 2}\right)$ dependence from the classical Hall-Petch relationship (1) (dotted line in Fig. 1) at small values of grain size $d$. Similar deviations are inherent to dependence observed experimentally [4-6,15,3639]) for mechanical characteristics (yield stress, microhardness) of real fine-grained copper materials (see Fig. 1).

(It should be noted that, in a detailed comparison of experimental data with theoretical predictions, it is worth to take into account the difference between conditions at which the reported dependences $\sigma\left(d^{-1 / 2}\right)$ have been experimentally measured. So, experimental points from references [38,39] (see Fig. 1) were taken in tension which, with lack of strain hardening, often is accompanied by plastic instability. At the same time, experimental points from Ref. [15] (see Fig. 1) were obtained by repeated annealing, known to strength nanocrystalline metals, so the samples compared in work [15] were not in the same state. The discussed difference between details of experiments is beyond a description of our first approximation model addressed the general aspects of plastic flow in fine-grained materials. However, the model suggested can serve as a basis for further, more detailed theoretical description of the deformation behavior exhibited by nanocrystalline materials at different conditions of loading.)

\section{Concluding remarks}

Thus, in this paper we have suggested a theoretical model describing plastic deformation in fine-grained materials as that occurring via such competing deformation mechanisms as conventional dislocation slip, grain boundary diffusional creep (Coble creep) and triple junction diffusional creep. For large grain size, a material obeys the classical Hall-Petch relationship (1) due to the dominant role of the conventional dislocation slip in grain interiors. The contribution of the grain boundary and triple junction diffusional creep mechanisms to plastic flow increases with reducing grain size $d$. This, in the framework of our model, causes experimentally observed (for a review, see [4-6]) deviations from the classical Hall-Petch relationship materials with grain size $d \leqslant 20 \mathrm{~nm}$.

It should be noted that the various-sized grains deforming by dislocation slip, Coble creep and triple junction diffusional creep form a coupled solid, in which case internal strains and stresses can buildup as a result of the action of different deformation mechanisms. The strain and stress inhomogeneities are not taken into account in our theoretical analysis dealing with the averaged model picture of plastic flow in fine-grained materials. In reality, if internal strains and stresses buildup in a grain (and its neighbouring grains), they effectively relax via the simultaneous cooperative action of the different deformation mechanisms in the grain (and its vicinity). The effect discussed can be involved into our theoretical description, using term of "interaction" of different channels (mechanisms) of plastic flow. This modification of the model suggested here is the subject of our further investigations.

In this paper we have described the only diffusional creep mechanisms as those associated with the active role of grain boundaries in plastically deformed fine-grained materials. In general, grain boundary sliding is capable of essentially contributing to plastic flow or even being the dominant deformation mechanism in nanocrystalline materials (with $d \leqslant 20 \mathrm{~nm}$ ) where the volume fraction of the grain boundary phase is extremely high. In doing so, triple junctions play the role as obstacles for grain boundary sliding [14] in contrast to their softening role in the situation where diffusional creep mechanisms dominate (see Fig. 1). In this context, the role of triple junctions in plastic deformation processes is crucial in identifying the dominant deformation mechanism (lattice dislocation slip, grain boundary sliding or diffusional creep) realized in mechanically loaded nanostructures. It is important for understanding the fundamentals of plastic deformation processes in nanocrystalline materials as well development of technologies based on plastic forming of nanostructures. 


\section{Acknowledgements}

We would like to greatly thank the referee for useful comments. This work was supported, in part, (for MYuG and IAO) by the Volkswagen Foundation (research project 05019225) and INTAS (grant 99-0216), (for MYuG) the Russian Research Council "Physics of Solid-State Nanostructures" (grant 97-3006), and (for IAO) the Office of US Naval Research (grant N00014-01-11020), NATO Scientific Affairs Division (grant PST.CLG.977712) and the Russian Foundation of Basic Researches (grant 01-02-16853).

\section{References}

[1] Gleiter H. Acta Mater 2000;48:1.

[2] Chow G-M, Ovid'ko IA, Tsakalakos T, editors. Nanostructured Films and Coatings, NATO Science Ser. Dordrecht: Kluwer; 2000.

[3] Roco MC, Williams RS, Alivisatos P, editors. Nanotechnology Research Directions, Dordrecht: Kluwer; 2000.

[4] Siegel RW, Fougere GE. Nanostruct Mater 1995;6:205.

[5] Hahn H, Padmanabhan KA. Nanostruct Mater 1995; 6:191.

[6] Song HW, Guo SR, Hu ZQ. Nanostruct Mater 1999; 11:203.

[7] Hall EO. Proc Phys Soc London B 1951;64:747.

[8] Petch NJ. J Iron Steel Inst 1953;174:25.

[9] Gryaznov VG, Gutkin MYu, Romanov AE, Trusov LI. J Mater Sci 1993;28:4359.

[10] Kim HS. Scr Mater 1998;39:1057.

[11] Kim HS, Estrin Y, Bush MB. Mater Sci Eng A 2001; 315:195.

[12] Konstantinidis DA, Aifantis EC. Nanostruct Mater 1998; 10:1111.

[13] Kim HS, Estrin Y, Bush MB. Acta Mater 2000;48:493.

[14] Hahn H, Mondal P, Padmanabhan KA. Nanostruct Mater 1997;9:603.

[15] Chokshi AH, Rosen A, Karch J, Gleiter H. Scr Metall 1989;23:1679.
[16] Masumura RA, Hazzledine PM, Pande CS. Acta Mater 1998;46:4527.

[17] Pande CS, Masumura RA, Armstrong RW. Nanostruct Mater 1993;2:323.

[18] Seattergood RO, Koch CC. Scr Mater 1992;27:1195.

[19] Malygin GA. Phys Solid State 1995;37:1248.

[20] Gutkin MYu, Ovid'ko IA, Pande CS. Rev Adv Mater Sci 2001;2:80.

[21] Gutkin MYu, Ovid'ko IA. Defects and Plasticity Mechanisms in Nanostructured and Non-crystalline Materials. St. Petersburg: Yanus; 2001 (in Russian).

[22] King AH. Interf Sci 1999;7:251.

[23] Palumbo G, Aust KT. Mater Sci Eng A 1989;113:139.

[24] Yin KM, King AH, Hsieh TE, Chen FR, Kai JJ, Chang L. Microsc Microanal 1997;3:417.

[25] Czubayko U, Sursaeva VG, Gottstein G, Shvindlerman LS. In: Weiland H, Adams BL, Rollett AD, editors. Grain Growth in Polycrystalline Materials. Pittsburg: TMS; 1998. p. 423.

[26] Osipov AV, Ovid'ko IA. Appl Phys A 1992;54:517.

[27] Gutkin MYu, Ovid'ko IA. Philos Mag A 1994;70:561.

[28] Owusu-Boahen K, King AH. Acta Mater 2001;49:237.

[29] Gottstein G, King AH, Shvindlerman LS. Acta Mater 2000;48:397.

[30] Horvath J, Birringer R, Gleiter H. Solid State Commun 1987;62:391.

[31] Schaefer H-E, Wurschum R, Gessmann T, Stockl G, Scharwaechter P, Frank W, et al. Nanostruct Mater 1995;6:869.

[32] Kolobov YuR, Grabovetskaya GP, Ratochka IV, Ivanov KV. Nanostruct Mater 1999;12:1127.

[33] Kolobov YR, Grabovetskaya GP, Ivanov KV, Valiev RZ, Lowe TC. In: Lowe TC, Valiev RZ editors. Investigations and Applications of Severe Plastic Deformation, NATO Science Ser. Dordrecht: Kluwer; 2000, p. 261.

[34] Gleiter H. Prog Mater Sci 1989;33:79.

[35] Rabukhin VB. Poverkhnost 1986;7:126 (in Russian).

[36] Youngdahl CJ, Sanders PG, Eastman JA, Weertman JR. Scr Mater 1997;37:809.

[37] Suryaanarayana R, Frey CA, Sastry SML, Waller BE, Bates SE, Buhro WE. J Mater Res 1996;11:439.

[38] Sanders PG, Eastman J, Weertman JR. Acta Mater 1997;45:4019.

[39] Sanders PG, Eastman JA, Weertman JR. In: Suryanarayana $\mathrm{C}$, Singh J, Froes FH, editors. Processing and properties of NC materials. Pittsburg: TMS; 1996. p. 397. 